\title{
PERSEPSI MAHASISWA KEPERAWATAN TENTANG PASIEN STANDAR OSCE DI INSTITUSI PENDIDIKAN DI YOGYAKARTA
}

\author{
Sunika Eka Puspasuci, Totok Harjanto* \\ Program Studi Ilmu Keperawatan, Fakultas Kedokteran Kesehatan Masyarakat dan Keperawatan, \\ Universitas Gadjah Mada, Yogyakarta, 55281, Indonesia \\ *)E-mail: toharjanto506@ugm.ac.id
}

Diterima: Agustus 2017, diterbitkan: Agustus 2018

\begin{abstract}
ABSTRAK
Objective Structured Clinical Examination (OSCE) merupakan salah satu metode evaluasi keterampilan klinik mahasiswa keperawatan. OSCE juga digunakan dalam blok 4.5 CCNS (Comprehensive Clinical Nursing Skills) yang bertujuan untuk mempersiapkan mahasiswa memasuki tahap pembelajaran klinik. Pembentukan OSCE sebagai metode penilaian membutuhkan beberapa persiapan diantaranya mempersiapkan pasien standar. Pasien standar berperan sebagai pasien OSCE. Penggunaan pasien standar dalam OSCE sangat diperlukan agar mahasiswa terbiasa untuk berinteraksi dengan pasien sesungguhnya di klinik. Tujuan Penelitian: Penelitian ini bertujuan untuk mengeksplorasi persepsi dan pengalaman mahasiswa tentang penggunaan pasien standar Objective Structured Clinical Examination blok 4.5 tahun ajaran 2014/2015 di Program Studi Ilmu Keperawatan FKKMK UGM. Metode: Penelitian ini dirancang menggunakan desain kualitatif deskriptif eksploratif. Dua belas mahasiswa pendidikan profesi Program Studi Ilmu Keperawatan FKKMK UGM periode September 2015-Oktober 2016 yang telah mengikuti blok 4.5 CCNS diwawancara tentang pengalaman mereka saat berinteraksi dengan pasien standar. Teknik wawancara mendalam menggunakan semi terstrukt ur sehingga pewawancara dapat mengembangkan pertanyaan. Data yang terkumpul dianalisis dengan menggunakan teknik content analysis. Hasil: Terdapat tiga tema utama yang menggambarkan persepsi dan pengalaman mahasiswa tent ang penggunaan pasien standar yaitu 1) persepsi mahasiswa tentang penggunaan pasien standar dengan dua kategori: pemahaman tentang peran pasien standar dan tipe pasien standar; 2) pengalaman berinteraksi dengan pasien standar: pengalaman yang bermanfaat, realistik dan kurang realistik; 3) Kinerja pasien standar digambarkan dengan penampilan dan respon pasien standar saat ujian OSCE. Kesimpulan: Penggunaan pasien standar saat OSCE blok 4.5 di PSIK FKKMK UGM membantu mahasiswa dalam menggambarkan kondisi klinik sebenarnya.
\end{abstract}

Kata kunci: Mahasiswa keperawatan, OSCE, pasien standar, pembelajaran klinik, sarjana keperawatan

\section{PERCEPTION OF NURSING STUDENTS ON STANDARDIZED PATIENTS IN OSCE AT EDUCATIONAL INSTITUTION IN YOGYAKARTA ABSTRACT}

Objective Structured Clinical Examination (OSCE) is one evaluation method to measure nursing students' clinical skills. OSCE also utilized in block 4.5 CCNS (Comprehensive Clinical Nursing Skills) in purpose to prepare student before following clinical rotation nursing education. OSCE as an assessment method requires some arrangements, including preparation of a standardized patients. Standardized OSCE patients necessary to accustom student's interaction with real patients at the clinical setting. Objective: This study aimed to explore students'perceptions and experiences during OSCE block 4.5 using standardized patients in the 2014/2015 academic year at School of Nursing Faculty of Medicine Public Health and Nursing Universitas Gadjah Mada. Methods: This study designed in an exploratory descriptive qualitative research. Twelve undergraduate clinical rotation nursing students of School of Nursing Faculty of Medicine Public Health and Nursing period September 2015 until October 2016 who has been passing through block 4.5 CCNS interviewed about their experience during interaction with standardized patient. An in-depth semi-structured interview used to explore 
students 'perception. Data were analyzed using content analysis technique. Results: Three main themes reflected students' perceptions and experiences identified during their interaction with standardized patients. The themes are 1) Students' perception on the use of standardized patient consists of two main categories: the understanding of standardized patient roles and standardized patient types; 2) Students 'interaction experience with the standardized patients: supportive, realistic and unrealistic experience; 3) Standardized patients' performance measured on the patients' appearance and responses during block 4.5 of OSCE. Conclusion: Use of standardized patient during OSCE block 4.5 at School of Nursing Faculty of Medicine Public Health and Nursing UGM help students to describe real clinical situations.

Keywords: clinical rotation nursing education, OSCE, undergraduate nursing students, standardized patient.

\section{LATAR BELAKANG}

Program Studi IImu Keperawatan Fakultas Kedokteran Universitas Gadjah Mada (PSIK UGM) merupakan salah satu program pendidikan akademik keperawatan profesional yang mencakup pendidikan sarjana dan klinik yang berorientasi pada "Community Oriented Nursing Education" dan berbasis kompetensi. Pelaksanaan proses pendidikan dilakukan dengan penerapan kemajuan teknologi kedokteran yang menyesuaikan dengan kebutuhan era globalisasi (Pertiwi, et al., 2015). Salah satunya proses pembelajaran dengan menerapkan pendekatan pembelajaran yang berfokus pada mahasiswa (student centered learning) seperti kegiatan diskusi kelompok (tutorial) dengan pendekatan problem based learning (PBL) dan Objective Structured Clinical Examination (OSCE) sebagai media evaluasi.

OSCE pertama kali diperkenalkan oleh Herden et al pada tahun 1975 yang dirancang untuk menilai keterampilan klinik dan kompetensi mahasiswa tingkat akhir (Rushforth, 2007). Sejak saat itu OSCE digunakan sebagai ujian formatif dan sumatif untuk menilai kompetensi keterampilan di berbagai disiplin ilmu baik kedokteran, keperawatan dan farmasi (Mårtensson \& Löfmark, 2013) dan sebagai sumber belajar serta alat untuk mengidentifikasi kesenjangan dan kelemahan dalam komunikasi dan keterampilan klinik. Sebagai alat uji yang valid, reliabel dan setting klinik yang mendekati nyata membuat penggunaan OSCE dalam penilaian kompetensi mahasiswa yang objektif dan restruktur (Nursalam \& Efendy, 2010).

Pelaksanaan OSCE di PSIK UGM sendiri dilaksanakan di skill laboratorium yang dimana suasana dan peralatan yang ada menyerupai klinik sebenarnya dan disesuaikan dengan tujuan pada setiap bloknya. OSCE juga digunakan sebagai salah satu komponen dalam penilaian dari blok 4.5 CCNS (Comprehensive Clinical Nursing Skills) dengan persentase penilaian sebesar $70 \%$. Blok 4.5 memiliki tujuan untuk mempersiapkan mahasiswa memasuki tahap pembelajaran klinik (Pertiwi, et al., 2015).

Penelitian dan pengembangan OSCE telah banyak dilakukan dan masih berlangsung hingga saat ini seperti uji validitas dan reliabilitas (Fallatah et al., 2015). Evaluasi penerapan OSCE di PSIK UGM sendiri sudah dilakukan oleh Fadzillah, (2014) yang mengevaluasi komponen OSCE secara menyeluruh. Pembentukan OSCE sebagai metode penilaian dibutuhkan beberapa persiapan diantaranya kurikulum/kompetensi klinik, penentuan waktu setiap stase, jumlah stase, logistik, penguji, pembiayaan, standard setting, pasien standar, penguji, dan post exam review (Zulharman, 2007).

Istilah pasien standar (standardized patients) diciptakan pertama kali oleh Howard Barrows pada tahun 1960s dengan pengertian bahwa seseorang yang dilatih untuk mengajar, penilaian, tujuan evaluasi dan secara konsisten menggambarkan skenario pasien, ataupun pasien sebenarnya sesuai dengan riwayat kesehatan(Churchouse \& McCafferty, 
2012). Penggunaan pasien standar sebagai metode pembelajaran telah banyak diterapkan dalam pendidikan keperawatan diantaranya untuk mengevaluasi komunikasi teraupetik (Webster, 2014). Selain itu juga penggunaan pasien standar dalam evaluasi formatif dapat meningkatkan kepercayaan siswa dalam praktek klinik (Wathen, Conde, \& Ortega, 2011).

Kontak mahasiswa sarjana dengan pasien dalam proses pendidikan sangat terbatas (Kowitlawakul et al., 2015). Masalah tersebut pun dialami oleh mahasiswa PSIK UGM. Oleh karena itu, penggunaan pasien standar dalam proses pendidikan sangat diperlukan agar mahasiswa terbiasa dalam menghadapi pasien di klinik dengan tanpa mengorbankan keselamatan pasien (Kamdar et al., 2013). Liaw et al. (2014) menyatakan bahwa penggunaan pasien standar membantu mahasiswa mempersiapkan masa transisi praktek klinik lebih baik.

\section{METODE}

Penelitian ini merupakan penelitian deskriptif eksploratif dengan pendekatan kualitatif(Creswell, 2010/2012). Pengambilan data dengan menggunakan teknik wawancara mendalam (indepth interview). Penelitian ini dilakukan di Program Studi Ilmu Keperawatan FK UGM dan sekitarnya pada tanggal 26 Januari 2016 sampai 12 Maret 2016.

Populasi penelitian ini adalah mahasiswa pendidikan profesi PSIK UGM periode September 2016 sampai Oktober 2017 yang telah mengikuti OSCE blok 4.5 tahun ajaran 2014/2015 dengan besar sampel yang digunakan berdasarkan atas kejenuhan data yaitu saat pengumpulan data tidak ditemukan lagi variasi informasi yang diberikan oleh partisipan. Pengujian keabsahan data dalam penelitian kualitatif terdiri dari credibility, transferability, dependability dan conformability (Creswell, 2010/2012). Peneliti menggunakan credibility dan transferrability untuk menguji keabsahan data penelitian ini. Uji creadibilitas dengan memperpanjang keikutsertaan dalam penelitian, triangulasi data dan member checking. Sedangkan uji transferability dengan mengutip perkataan asli partisipan. Pengumpulan data dalam dengan menggunakan wawancara mendalam dengan menggunakan semi-structured interviews sesuai panduan wawancara yang telah dibuat peneliti berdasarkan literature review. Panduan wawancara berisi persepsi mahasiswa tentang penggunaan pasien standar, pengalaman mahasiswa saat berinteraksi, pengaruh penggunaan pasien standar dalam membantu persiapan pendidikan profesi dan kinerja pasien standar saat OSCE. Pengambilan data dilakukan dengan menggunakan semi-structured interviews yang dimana saat wawancara peneliti dapat mengembangkan pertanyaan sesuai yang mendukung tujuan penelitian (Streubert, 2010). Data yang terkumpul dianalisis data dengan menggunakan content analysis (Elo \& Kyngs, 2008).

\section{HASIL \\ Karakteristik Partisipan Penelitian}

Partisipan dalam penelitian ini adalah mahasiswa pendidikan profesi angkatan 2015 Program Studi Ilmu Keperawatan yang telah mengikuti ujian OSCE CCNS tahun ajaran 2014/2015. Jumlah partisipan dalam penelitian ini berjumlah 12 mahasiswa yang dipilih berdasarkan kriteria inklusi yang telah ditetapkan oleh peneliti. Setiap partisipan memiliki riwayat stase klinik yang berbeda dengan rata-rata sudah melewati rata-rata 21 minggu masa klinik dan sudah melewati salah satu stase klinik yang menggunakan pasien standar saat ujian OSCE CCNS. Hal ini berpengaruh pada informasi yang diberikan tentang persepsi dan pengalaman saat berinteraksi dengan pasien standar. 
Tabel 1. Karakteristik Partisipan Mahasiswa

\begin{tabular}{|c|c|c|c|c|c|}
\hline No. & $\begin{array}{c}\text { Kode } \\
\text { Partisipan }\end{array}$ & $\begin{array}{c}\text { Jenis } \\
\text { Kelamin }\end{array}$ & Usia & Pendidikan & Riwayat Stase Klinik \\
\hline 1. & $\mathrm{RF}$ & $P$ & 22 & S1 & PKD, KMB, Gadar \\
\hline 2. & FU & $P$ & 23 & S1 & $\begin{array}{l}\text { PKD, Jiwa, Gadar, } \\
\text { Manajemen, Anak }\end{array}$ \\
\hline 3. & $A C$ & $\mathrm{P}$ & 22 & S1 & PKD, KMB, Gadar \\
\hline 4. & NA & $\mathrm{P}$ & 22 & S1 & PKD, Komunitas, KMB \\
\hline 5. & SK & $P$ & 22 & S1 & $\begin{array}{l}\text { PKD, Jiwa, Gadar, } \\
\text { Manajemen, Anak }\end{array}$ \\
\hline 6. & PD & $P$ & 23 & S1 & PKD, KMB, Jiwa \\
\hline 7. & YA & $P$ & 23 & S1 & $\begin{array}{l}\text { PKD, Jiwa, Gadar, } \\
\text { Manajemen, Anak }\end{array}$ \\
\hline 8. & LF & $P$ & 23 & S1 & PKD, Komunitas, KMB \\
\hline 9. & DK & $P$ & 22 & S1 & PKD, Komunitas, KMB \\
\hline 10 & YS & $\mathrm{P}$ & 22 & S1 & PKD, Komunitas, KMB \\
\hline 11. & TK & $P$ & 23 & S1 & $\begin{array}{l}\text { PKD, Gadar, Jiwa, } \\
\text { Manajemen, Maternitas }\end{array}$ \\
\hline 12. & FD & $P$ & 22 & S1 & $\begin{array}{l}\text { PKD, Gadar, Jiwa, } \\
\text { Manajemen, Maternitas }\end{array}$ \\
\hline
\end{tabular}

Sumber : Data Primer, 2016

\section{Hasil Analisis Data}

Berdasarkan analisis data dengan cara penggunaan pasien standar saat OSCE content analysis didapatkan gambaran CCNS blok 4.5 seperti yang ditampilkan pada persepsi dan pengalaman mahasiswa tentang tabel 2 di bawah ini.

Tabel 2. Hasil Analisis Hasil

\begin{tabular}{|c|c|c|c|c|}
\hline No. & Tema & Kategori & Koding & Contoh Pernyataan \\
\hline 1. & $\begin{array}{l}\text { Persepsi } 1.1 \\
\text { mahasiswa } \\
\text { te } n \text { t a n g } \\
\text { penggunaan }\end{array}$ & $\begin{array}{l}\mathrm{P} \text { e } \mathrm{m} \text { a } \mathrm{h} \text { a } \mathrm{m} \text { a } \mathrm{n} \\
\text { tentang peran } \\
\text { pasien standar }\end{array}$ & $\begin{array}{l}\text { Familier/ tidak } \\
\text { dengan istilah } \\
\text { pasien standar }\end{array}$ & $\begin{array}{l}\text { "Pasien standar? Aku taunya } \\
\text { pasien safety sama pasien centered } \\
\text { care"(R3) }\end{array}$ \\
\hline
\end{tabular}

pasien standar

"Kalau dari katanya tu ya...pasien standar mungkin pasien yang sudah dipersiapkan sebagai probandus"(R1)

Pasien standar "Jadi pasien sih...apa ya...em adalah pasien berperan di ya OSCE kita. Jadi OSCE pokomen jadi pasien pas kita, kan nggak real ya misalkan nanti ya luka kayak gitu pokoknya jadi pasien" (R4) 


\begin{tabular}{|c|c|c|c|c|c|}
\hline No. & Tema & & Kategori & Koding & Contoh Pernyataan \\
\hline & & 1.2 & Tipe pasien standar & $\begin{array}{l}\text { Pasien standar } \\
\text { profesional }\end{array}$ & $\begin{array}{l}\text { "...Probandusnya dari luar, nggak } \\
\text { pernah ketemu, nggak pernah liat } \\
\text { sih. Emang khusus didatangkan } \\
\text { untuk skill itu."(R9) }\end{array}$ \\
\hline & & & & Pasien nyata & $\begin{array}{l}\text { "....jadi kayak gitu orang yang bener- } \\
\text { bener orang dengan gangguan ya } \\
\text { udah maintenance sih ya probandus } \\
\text { OSCE yang jiwa itu..."(R4) }\end{array}$ \\
\hline & & & & Staf PSIK & $\begin{array}{l}\text { "..... Oh iya iya waktu itu sama mas- } \\
\text { mas di PSIK..."(R9) }\end{array}$ \\
\hline & & & & Mahasiswa PSIK & $\begin{array}{l}\text { "Komunitas itu aku sama temen } \\
\text { sendiri..."(R4) }\end{array}$ \\
\hline & & & & Penguji/Dosen & $\begin{array}{l}\text { "manajemen itu probandusnya } \\
\text { dosen sendiri."(R10) }\end{array}$ \\
\hline \multirow[t]{3}{*}{2.} & $\begin{array}{l}\text { Pengalaman } \\
\text { mahasiswa } \\
\text { berinteraksi } \\
\text { dengan pasien } \\
\text { standar }\end{array}$ & 2.1 & Bermanfaat & Pengkajian & $\begin{array}{l}\text { "...Terus dan kita itu orang } \\
\text { maksudnya kita orang belum kenal } \\
\text { jadi kayak kita mengkaji beneran, } \\
\text { terus menggali kayak manajemen } \\
\text { halusinasi ya anggap aja itu. Kita } \\
\text { bener-bener harus walaupun ada } \\
\text { berapa berapa ini kan itu ada berapa } \\
\text { cara maksudnya yang dikaji apa aja } \\
\text { gitu kan..." (R4) }\end{array}$ \\
\hline & & & & Interaksi & $\begin{array}{l}\text { "..Meskipun itu kebanyakan orang } \\
\text { akademik yang udah kita kenal tapi, } \\
\text { gimana-gimana kita menempatkan } \\
\text { diri, ternyata kita menemukan beliau } \\
\text { di klinik misalkan kayak gitu. Jadi ya, } \\
\text { gimana komunikasi teraupetiknya } \\
\text { gitu-gitu."(R1) }\end{array}$ \\
\hline & & & & $\begin{array}{l}\text { Meningkatkan } \\
\text { keterampilan } \\
\text { komunikasi }\end{array}$ & $\begin{array}{l}\text { "Kalo ada probandus tu kita belajar } \\
\text { komunikasi. Karena kalo ketemu } \\
\text { pasien langsung emang komunikasi } \\
\text { itu penting kayak gitu. "(R5) }\end{array}$ \\
\hline
\end{tabular}

2.2 Realistik Realistik

"Nggak sih nggak ada yang aneh aneh. Cuman sewajarnya pasien sih kalo menurut aku. Yang emang aku temuin di bangsal ya emang kayak gitu sih kadang kadang..... Kondisinya diem aja. Kalo misalnya atau nggak males. Tapi yang paling enak kalo diajak ngomong ya itu ya enak kayak gitu." (R 9) 


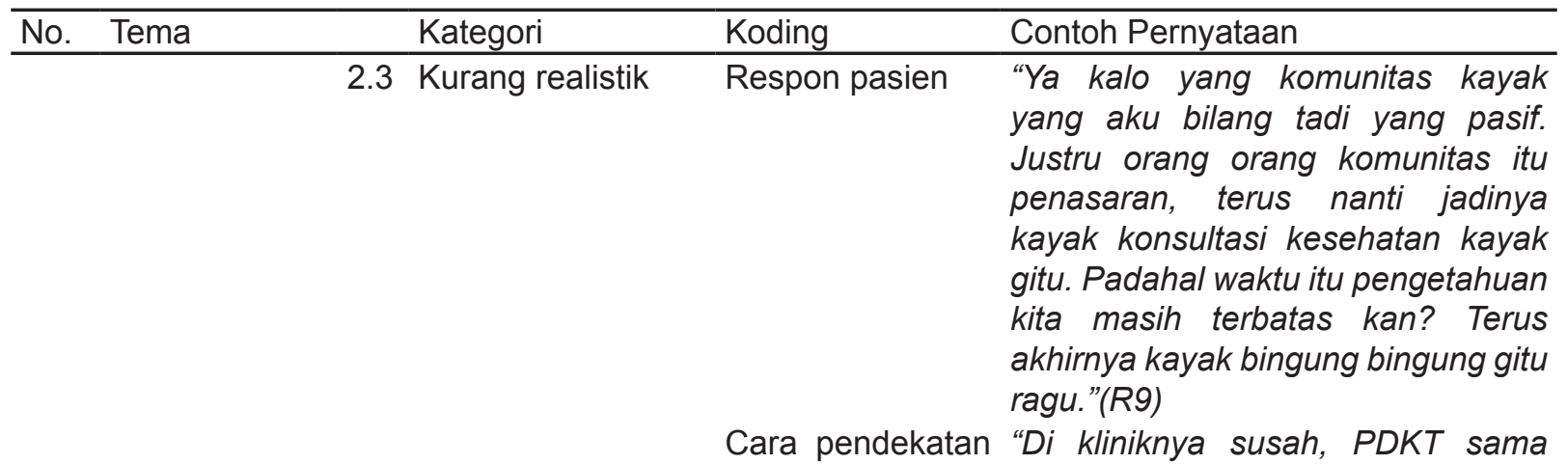
pasien

3. Kinerja pasien 3.1 Penampilan pasien Sesuai kasus standar standar

Kurang sesuai pasiennya susah banget, mau bina hubungan saling percaya itu susah banget, deketin pasiennya cuman he he he iya nggak gitu, padahal kalau di sini kan kasarannya kita wes terbina hubungan saling percaya kan ya langsung la la la gitu kan di sana nggak.."(R6)

"...Kalau data dapet semua, alhamdulilah pas itu, pas ujiannya semuanya terjawab sama yang manajemen bisa tersalurkan dengan baik ya itu tadi karena kan probandus ya sebenernya tahu kan sebenernya apa yang kita butuhkan jadi membantu gitu loh, kasarannya kan gitu aja, cukup sesuai lah."(R6) “...di komunitas tentang penyuluhan itu, menurut mbak sih kurang gimana ya, kurang mendalami kasusnya, soalnya waktu itu kan kurang sesuai sama kasusnya, jadi kan kasusnya waktu itu tentang apa ya pasien post stroke apa ya kalau nggak salah, jadi dia tu abis paralisis paralisis gitu loh, jadi ada ada kelemahan terus dia itu mengalami kelemahan, dia abis direhab terus mengalami kelemahan nah diajarkan tentang ROM cuman kondisi pasiennya tu nggak sesuai sama yang kasusnya harusnya kan dia masih ada kelemahan agak agak kaku atau gimana, tapi dia tu kayak orang biasa gitu loh.."(R5) 


\begin{tabular}{|c|c|c|c|c|c|c|}
\hline No. & Tema & & Kategori & & Koding & Contoh Pernyataan \\
\hline & & 3.2 & $\begin{array}{l}\text { Respon } \\
\text { standar }\end{array}$ & pasien & Kooperatif & $\begin{array}{l}\text { "Kalau sepengalamanku sih kalau } \\
\text { yang kemaren pas yang di restraint } \\
\text { itu pasiennya kooperatif sih"(R2) }\end{array}$ \\
\hline & & & & & $\begin{array}{l}\text { Aktif/memberikan } \\
\text { feedback }\end{array}$ & $\begin{array}{l}\text { "lya. Dia terus aktif nanya kayak } \\
\text { gitu, tapi nggak mempersulit. Kalo } \\
\text { pas aku loh dek kan beda beda } \\
\text { probandusnya"(R7) }\end{array}$ \\
\hline & & & & & Pasif & $\begin{array}{l}\text { "...Pak H cuma kayak iya.. lya .. } \\
\text { Kayak gitu doang. "(R8) }\end{array}$ \\
\hline & & & & & $\begin{array}{l}\text { Tidak } \\
\text { memberikan } \\
\text { feedback }\end{array}$ & $\begin{array}{l}\text { ".....Berperan ganda. Tapi ya cuman } \\
\text { mereka cuman dengerin nggak yang } \\
\text { jawab iya, nggak yang nggak itu } \\
\text { nggak.."(R11) }\end{array}$ \\
\hline
\end{tabular}

Sumber: Data Primer, 2016

\section{DISKUSI}

Mahasiswa lebih familier dengan istilah probandus dibandingkan istilah pasien standar. Hal ini karena di PSIK FK UGM sendiri penyebutan untuk seseorang yang berperan sebagai pasien OSCE menggunakan istilah probandus bukan pasien standar. Mahasiswa memahami pasien standar/probandus sebagai seseorang yang berperan sebagai pasien yang memerankan kasus tertentu. Hal ini senada dengan definisi pasien standar dari Gliva \& Convey (2015) yaitu pasien standar diartikan sebagai seseorang yang menggambarkan skenario yang telah ditentukan. Mahasiswa menyebutkan tipe pasien standar yang terlibat dalam ujian OSCE blok 4.5 diantaranya pasien nyata, pasien standar profesional, staf PSIK, mahasiswa PSIK dan dosen/penguji OSCE. Pasien nyata/asli yang terlibat merupakan pasien jiwa yang kondisinya sudah stabil yang ikut diperbantukan untuk menguji mahasiswa dalam manajemen halusinasi. Sedangkan pasien standar profesional adalah pasien standar yang pernah digunakan sebelumnya ataupun pasien yang sengaja didatangkan khusus untuk keterampilan tertentu. Hal ini sesuai dengan kriteria pasien standar menurut HPEQ Project (2008), yaitu salah satunya adalah pasien standar yang sudah punya pengalaman dan pelatihan bagaimana cara menjadi pasien standar. Penggunaan staf, mahasiswa dan dosen karena ketiadaan pasien standar profesional. Keterlibatan staf dan mahasiswa sebagai pasien standar membuat mahasiswa lebih nyaman dalam melakukan keterampilan karena sudah saling mengenal sebelumnya. Selain itu juga staf dan mahasiswa cenderung memiliki sifat subjektif yang tinggi seperti membantu dan mengingatkan mahasiswa jika ada tahapan keterampilan yang belum dikerjakan ataupun membuat refleks neurologis palsu. Sifat subjektif ini membuat mahasiswa sangat diuntungkan akan tetapi di sisi lain mahasiswa tidak bisa mengeksplorasi kemampuannya melakukan keterampilan dengan maksimal baik dari segi cara komunikasi, interaksi maupun cara pendekatan yang efektif untuk membangun trust dengan pasien. Sedangkan penggunaan dosen sekaligus pasien standar membuat mahasiswa merasa tidak dihargai karena tidak ada feedback yang diberikan untuk keterampilan yang mereka lakukan. Mahasiswa hanya mempraktikkan apa yang telah mereka pelajari saja tanpa memahami kegunaan melakukan keterampilan tersebut. Penggunaan staf dan mahasiswa PSIK serta dosen sebagai pasien standar tidak sesuai dengan kriteria pasien standar yang 
ditetapkan oleh HPEQ Project (2008) yang menyatakan pasien standar yang digunakan tidak berasal dari profesi kedokteran (mahasiswa kedokteran, perawat, dokter, bidan, residen).

Mahasiswa menyebutkan penggunaan pasien standar sangat bermanfaat, realistik dan juga kurang realistik untuk menggambarkan kondisi klinik yang mereka jalani sekarang.

Pasien standar bermanfaat membantu mahasiswa dalam pengkajian riwayat kesehatan pasien. Kowitlawakul et al. (2014) dalam penelitiannya menyebutkan pasien standar membantu mahasiswa Pascasarjana keperawatan mendapatkan riwayat pengkajian dan gejala yang ada sesuai kasus. Selain itu pasien standar juga membantu mahasiswa dalam penggambaran interaksi yang akan dilakukan saat mereka di klinik. Bahkan ada mahasiswa yang menyebutkan cara interaksi yang mereka lakukan saat dengan pasien standar hampir sama dengan saat mereka berinteraksi dengan pasien nyata. Walaupun cara pendekatan yang dilakukan sedikit berbeda seperti lebih banyak basa basi kepada pasien. Hal ini senada dengan yang laporkan oleh Bornais et al. (2012), penggunaan pasien standar memiliki dampak yang signifikan pada pengalaman klinis mahasiswa keperawatan baik cara berinteraksi/menanggapi pasien dan membantu mereka berpikir lebih kritis.

Penggunaan pasien standar juga bermanfaat dalam peningkatan keterampilan komunikasi mahasiswa. Lin et al. (2013) mengungkapkan bahwa penggunaan pasien standar dalam ujian OSCE membuat kemampuan keterampilan komunikasi mahasiswa pascasarjana keperawatan meningkat secara signifikan. Selain itu juga mahasiswa merasa komunikasi yang mereka lakukan dengan pasien standar begitu berarti dalam menentukan kata-kata apa saja yang akan mereka sampaikan ke pasien nantinya. Hal senada juga diungkapkan oleh King, Conrad, \& Ahmed (2013), mahasiswa mampu menentukan cara komunikasi yang efektif dan menjadi komunikator yang baik untuk pasien. Pasien standar selain bermanfaat dalam pengkajian, interaksi dan meningkatkan komunikasi, juga meningkatkan sikap kehati-hatian mahasiswa dalam melakukan tindakannya dibandingkan saat berinteraksi dengan phantom. Menurut Defenbaugh \& Chikotas (2015), pasien standar meningkatkan kesadaran diri dan mahasiswa keperawatan lebih berhati-hati dalam melakukan keperawatan kepada pasien dikarenakan mereka punya respon.

Temuan yang lainnya, mahasiswa menyatakan pasien standar sangat realistik. Gejala dan tingkah laku/sikap yang digambarkan oleh pasien standar seperti yang digambarkan oleh pasien di klinik. Hal ini sesuai dengan penelitian Kowitlawakul et al. (2015) bahwa mahasiswa mengira pasien standar adalah pasien nyata dimana gejala seperti memar, luka, warna kulit yang tergambar tampak sangat realistik. Selain itu kasus yang ada di OSCE sama dengan kasus yang ada di klinik. Mahasiswa menyatakan pasien standar sangat akurat menggambarkan kasus yang dilihat di klinik (Slater et al., 2016). Terlepas gejala yang ditunjukkan oleh pasien standar sama dengan yang ada di klinik, mahasiswa menemukan cara komunikasi dan respon yang diberikan oleh pasien standar masih kurang sesuai dengan apa yang diberikan oleh pasien di klinik. Cara pendekatan dan komunikasi yang digunakan di klinik lebih informal dibandingkan saat ujian yang sangat kaku dan terpaku dengan dengan check list. Hal ini didukung oleh Defenbaugh \& Chikotas (2015), komunikasi yang dilakukan di klinik lebih fleksibel dan terkadang tidak hanya terfokus pada kondisi pasien akan tetapi lebih 
pada mendengarkan keluh kesah pasien yang umum dan tidak berkaitan dengan penyakit sama sekali. Selain itu beberapa pasien standar tidak mampu memberikan feedback yang seharusnya mereka berikan. Padahal feedback dari pasien standar sangat penting untuk melatih kemampuan mahasiswa menanggapi dan berespon yang sesuai (Rickles et al., 2009).

Kinerja pasien standar saat OSCE blok 4.5 digambarkan menjadi dua kategori yaitu penampilan dan respon pasien standar. Penampilan pasien standar dilihat dari kesesuaian akting yang diperankan oleh pasien standar. Mahasiswa menyatakan pasien standar saat OSCE sudah sesuai dengan kasus yang mereka dapatkan. Kesesuaian ini dilihat dari gejala yang digambarkan, cara interaksi maupun kondisinya yang ditunjukkan. Kesesuaian tersebut membuat mahasiswa bisa mempraktikkan keterampilan dengan maksimal. Sedangkan ada juga pasien standar yang belum sesuai dengan kasus yang mereka dapatkan seperti respon dan akting.

Respon yang diberikan oleh pasien standar untuk merespon apa yang dilakukan oleh mahasiswa sangat beragam seperti kooperatif, aktif menanggapi, pasif bahkan tidak memberikan feedback sama sekali hanya diam saja. Giesbrecht et al. (2014) melaporkan pasien standar memberikan respon yang positif atas keterampilan yang dilakukan oleh mahasiswa. Selain itu juga respon yang diberikan oleh pasien standar juga sangat mempengaruhi tingkat kecemasan mahasiswa saat ujian yaitu kecemasan mereka berkurang (Kameg et al., 2014).

\section{SIMPULAN}

Mahasiswa lebih familier dengan istilah probandus dibandingkan pasien standar dalam penyebutan pasien OSCE. Mahasiswa mendefinisikan pasien standar sebagai seseorang yang berperan sebagai pasien sesuai dengan kasus tertentu. Selain itu pengalaman berinteraksi dengan pasien standar saat OSCE blok 4.5 sangat bermanfaat, realistik dan kurang realistik menggambarkan kondisi klinik. Sedangkan penampilan pasien standar ada yang sesuai dengan kasus dan ada juga yang tidak dimana respon yang diberikan sangat bervariasi mulai dari yang positif maupun negatif.

Penelitian selanjutnya sebaiknya penelitian tidak hanya dilihat dari perspektif mahasiswa akan tetapi melibatkan subjek lain yang terlibat aktif dalam pelaksanaan OSCE CCNS seperti laboran, dosen dan pasien standar/probandus sendiri dan perlunya menentukan perumusan pasien standar yang ada di PSIK UGM.

\section{DAFTAR PUSTAKA}

Bornais, J. a K., Raiger, J. E., Krahn, R. E., El-Masri, M. M. (2012). Evaluating undergraduate nursing students' learning using standardized patients. $J$. Prof. Nurs, 28(5): 291-296.

Churchouse, C. \& McCafferty, C. (2012). Standardized Patients Versus Simulated Patients: Is There a Difference? Clinical Simulation in Nursing, 8: e363-e365.

Creswell, J. W. (2012). Research design: Qualitative, quantitative and mixed methods approaches ( $3^{\text {rd }}$ edition). (Alih bahasa: Achmad Fawaid). Yogyakarta: Pustaka Pelajar. Yogyakarta. (Buku asli diterbitkan 2010).

Defenbaugh, N. \& Chikotas, N. E. (2015). The outcome of interprofessional education: Integrating communication studies into a standardized patient experience for advanced practice nursing students. Nurse Education in Practice, 16(1): 176181.

Elo, S. \& Kyngs, H. (2008) The qualitative content analysis process. Journal of 
Advanced Nursing, 62(1): 107-115.

Fadzillah, R. A. (2014). Evaluasi pelaksana objective structured clinical examination berdasarkan persepsi mahasiswa di Program Studi IImu Keperawatan Fakultas Kedokteran UGM (Skripsi). Fakultas Kedokteran Universitas Gadjah Mada, Yogyakarta, Indonesia.

Fallatah, H.I., Tekian, A., Park, Y., Al Shawa, L., 2015. The validity and reliability of the sixth-year internal medical examination administered at the King Abdulaziz University Medical College. BMC Medical Education, 15: 10.

Giesbrecht, E., Wener, P. F., Pereire, G. M. (2014). A mixed methods study of student perceptions of using standardized patient for learning and evaluation. Advances in Education and Practice, 5: 241-255.

Gliva, G. \& Mc Convey. (2015). Simulated family and healthcare professionals: Consent for organ transplantation. In: Nestel, D. \& Bearman, M. Simulated patient methodology: Theory, evidence and practice, First Edition. John Wiley \& Sons, Ltd.

HPEQ Project (Health Professional Education Quality Project). (2011). Panduan penyelenggaran ujian OSCE. Jakarta: Kementrian Pendidikan dan Kebudayaan Republik Indonesia.

Kamdar, G., Kessler, D. O., Tilt, L., Srivastava, G., Khanna, K., Chang, T.P., Balmer, D., Auerbach, M., (2013). Qualitative evaluation of just-in-time simulation-based learning: The learners' perspective. Simul. Healthc, 8(1):43-48.

Kameg, K. M., Szpak, J. L., Cline, T. W., \& Mcdermott, D. S. (2014). Utilization of standardized patients to decrease nursing student anxiety. Clinical Simulation in Nursing, 10(11): 567-573.

King, A. E. A., Conrad, M., Ahmed, R. A. (2013). Improving collaboration among medical, nursing and respiratory therapy students through interprofessional simulation. J. Interprofessional Care, 27(3): 269-271.

Kowitlawakul, Y., Chow, Y.L., Salam, Z.H.A., Ignacio, J. (2015). Exploring the use of standardized patients for simulationbased learning in preparing advanced practice nurses. Nurse Education Today, 35(7): 894-899.

Liaw, S. Y., Koh, Y., Dawood, R., Kowitlawakul, Y., Zhou, W., Lau, S.T., (2014). Easing student transition to graduate nurse: A Simulated Professional Learning Environment (SIMPLE) for final year student nurses. Nurse Education Today, 34(12): 259-264.

Lin, E. C., Chen, S. L., Chao, S. Y., Chen, Y. C. (2013). Using standardized patients with immediate feedback and group discussion to teach interpersonal and communication skills to advanced practice nursing students. Nurse Education Today, 33(6): 677-683.

Mårtensson, G. \& Löfmark, A. (2013). Implementation and student evaluation of clinical final examination in nursing education. Nurse Education Today, 33(12): 1563-1568.

Nursalam, \& Efendy, F. (2010). Pendidikan dalam keperawatan. Jakarta: Salemba Medika.

Pertiwi, A. A. P., Nisman W. A., Akhmadi., Purwanta., Lusmilasari L., Widyawati, Pangastuti, H. S., ..., Sunaryo. (2015). Comprehensive Clinical Nursing Skills (CCNS) (4 ${ }^{\text {th }}$ edition). Yogyakarta: Program Studi IImu Keperawatan Fakultas Kedokteran UGM.

Rickles N. M., Tieu, P., Myers, L., Galal, S., Chung, V. (2009). The impact of a standardized patient program on student learning of communication skills. Am J Pharm Educ 19, 73(1): 4. 
Rushforth, H. E. (2007). Objective Structured Clinical Examination (OSCE): Review of literature and implications for nursing education. Nurse Education Today, 27(5): 481-490.

Slater, L. Z., Bryant, K. D., Vicky Ng. (2016). Nursing Student Perceptions of Standardized Patient Use in Health Assessment. CIINICAL Simulation in Nursing, 12(9): 368-376.

Streubert, H. J., Carpenter, D. R., (2010). Qualitative research in nursing: Advancing the humanistic imperative (5th edition). New York, USA: Lippincott Williams \& Wilkins.

Wathen, P., Conde, M. \& Ortega, A. (2011). Using Standardized Patients. Rumania: Workshop EMAE.

Webster, D. (2014). Using standardized patients to teach therapeutic communication in psychiatric nursing. Clinical Simulation Nursing, 10(2): e81e86.

Zulharman. (2007). Objective structured clinical examination (OSCE). Fakultas Kedokteran Universitas Riau. Retrieved from http://zulharman.staff.unri. ac.id/2007/06/18/objective-structure clinicalexamination-osce/ 